\title{
Optical Coherence Tomography Morphological
} Features Following Modified Internal Limiting Membrane Surgical Technique In Traumatic Macular Holes

This article was published in the following Dove Press journal: Clinical Ophthalmology

\author{
Hammouda Hamdy Ghoraba' \\ Mahmoud Leila $\mathbb{D}^{2}$ \\ Hashem Ghoraba $\mathbb{D I}^{3}$ \\ Mohamed Amin Heikal (iD) ${ }^{4}$ \\ Hosam Othman Mansour ${ }^{5}$ \\ 'Faculty of Medicine, Tanta University, \\ Tanta, Egypt and Medical Director, \\ Magrabi Eye Hospital, Tanta, Egypt; \\ ${ }^{2}$ Retina Department, Research Institute \\ of Ophthalmology, Giza, Egypt; ${ }^{3}$ Magrabi \\ Eye Hospital, Tanta, Egypt; ${ }^{4}$ Faculty of \\ Medicine, Benha University, Benha, Egypt; \\ ${ }^{5}$ Faculty of Medicine, Al Azhar University, \\ New Damietta City, Egypt
}

Objective: To describe the optical coherence tomography (OCT) findings in terms of macular hole closure and ellipsoid zone (EZ) recovery following modified internal limiting membrane (ILM) surgical technique in traumatic macular holes (TMH).

Methods: The study was a retrospective case series that recruited 16 consecutive patients with TMH. Following vitrectomy (PPV), we performed modified ILM surgical technique (IFT) in which ILM peel was stopped at the edges of the hole forming a floating ILM flap. Primary outcome measures were pattern of TMH closure and recovery of EZ. Student's $T$ test and Pearson's correlation coefficient were used for statistical analysis.

Results: The study had 16 eyes of 16 patients. Mean baseline minimum linear diameter (MLD) was $562 \mu$. Mean baseline best-corrected visual acuity (BCVA) was $1.4 \log$ MAR. Upattern closure occurred in $50 \%$ of eyes, V-pattern closure occurred in $31.2 \%$ of eyes, whereas W-pattern closure occurred in $18.7 \%$ of eyes. Mean BCVA improvement was 5 lines (p 0.02). Failure of recovery of EZ was detected in $75 \%$ of eyes. In the present series, neither pre-operative MLD nor time lapse prior to surgery were significant factors in determining the closure pattern of TMH, the grade of EZ recovery or final BCVA.

Conclusion: Modified IFT is effective in promoting macular hole closure and improving visual acuity in patients with TMH. The technique does not promote recovery of EZ.

Keywords: modified ILM surgical technique, traumatic FTMH, ILM peel adjuvants, ILM blue-assisted ILM peel, ellipsoid zone recovery

\section{Introduction}

Traumatic macular holes (TMH) constitute $9 \%$ of all macular holes. ${ }^{1}$ The pathogenetic mechanisms underlying development of TMH inflict multiple challenges for favorable anatomical and functional outcomes despite advances in modern macular hole surgery. Different types of ocular trauma converge on a common track that ends in tissue loss in the macular area. TMH could develop immediately due to direct rupture following penetrating ocular trauma, sudden anteroposterior compression of the globe in a blunt trauma; the so-called trampoline effect, or indirectly through a shock wave of Nd:YAG laser or chorioretinitis sclopetaria. Delayed TMH formation could develop subsequent to tissue degeneration following commotioretina. $^{2-6}$ The visual outcome of surgery is even aggravated by several co-morbidities inherent to the inciting trauma, including frequent large hole size, associated
Correspondence: Mahmoud Leila

Retina Department, Research Institute of Ophthalmology, 2, Al-Ahram Street, Giza, Egypt

Tel +20I 286644025

Email mahmoudleila@yahoo.com 
atrophy of the retinal pigment epithelium (RPE), sub-retinal hemorrhage or choroidal rupture. ${ }^{7}$ A reasonable surgical approach for $\mathrm{TMH}$ would be a technique that combines stimulus for glial cell proliferation to close the full-thickness defect while avoiding inflicting further damage to the RPE at the base of the hole that is already compromised by trauma. ${ }^{8}$ Recently, Casini et al, ${ }^{9}$ described a modified inverted internal limiting membrane (ILM) flap technique for large idiopathic macular holes that evaded any manipulation of the ILM as massaging the flap to cover the hole or tucking it inside the hole. The technique consisted of peeling off the ILM from the entire circumference of the hole without removing it entirely from the retinal surface, rather it was left attached at the hole edges. This technique had several advantages. Firstly, it eliminated the ILM template on which glial cells would proliferate and perpetuate hole opening through tangential traction, while the attached edges of the ILM provided a stimulus that re-directed the glial cell proliferation into bridging the full-thickness defect. Secondly, it defrayed any manipulation that might inflict further damage to the RPE at the base of the hole. The aim of the present study is to explore the outcome of the modified inverted ILM flap technique in $\mathrm{TMH}$ in terms of closure pattern and EZ recovery.

\section{Patients And Methods}

The study constituted a retrospective data analysis of all patients with TMH who were treated in a retina tertiary care center; Magrabi Eye Hospital (Tanta branch), Egypt, during the past 3 years. All recruited patients did not have prior surgical intervention. Baseline assessment included age, sex, laterality, nature of blunt ocular trauma and time lapse between sustaining trauma and first presentation. Baseline BCVA was recorded in decimal notation and converted to $\log$ MAR value for statistical analysis. Clinical examination included slit-lamp biomicroscopy and peripheral retinal examination using indirect ophthalmoscopy with $360^{\circ}$ - scleral indentation. On OCT examination, recruited patients had to have full-thickness macular hole (FTMH) that involved the entire neurosensory retina. The minimum linear diameter (MLD) of the hole was measured at baseline. ${ }^{10}$ OCT scan was performed using one of two spectral-domain OCT (SD-OCT) versions, Cirrus HD-OCT 4000 (Carl Zeiss Meditech, Inc. Dublin, California, USA), or Heidelberg Spectralis (Heidelberg Engineering, Inc., Heidelberg, Germany), so that same OCT machine was used for pre-operative and post-operative evaluation for any given patient. The selected scanning protocols were 5-line raster and 3dimensional $512 \times 128$ cube centered onto the fovea. Eligible patients had to have 1 month observation period after trauma to allow for spontaneous hole closure. After the observation period, patients underwent surgery if OCT examination revealed persistent open hole, or increased MLD of the hole compared to baseline measurement. Any patient with a history of previous macular hole surgery or signs of other complications attributed to the initial inciting trauma and that could have altered OCT morphological features as retinal detachment, choroidal rupture bisecting the fovea, or could have a negative impact on final BCVA as associated optic nerve pathology was excluded from the study. Similarly, the study excluded patients who did not complete at least 4-month follow-up period. Surgical intervention for all patients included standard pars plana vitrectomy (PPV) along with modified ILM flap surgical technique. Patients with concomitant cataract that was deemed dense enough to preclude adequate ILM surgery had phacoemulsification and foldable intra-ocular lens (IOL) implantation within the capsular bag before proceeding to vitreous surgery. Primary outcome measures were detection of pattern of TMH closure whether $\mathrm{U}, \mathrm{V}$ or $\mathrm{W},{ }^{11}$ and grade of EZ recovery. Secondary outcome measure was exploring whether pre-operative MLD and time interval between onset of trauma and surgery influenced the pattern of hole closure and BCVA achieved after surgery. The institutional review board of Magrabi Eye hospital approved this study. The review board required that patients undertaking diagnostic tests or surgical procedures received thorough explanation about their disease condition, the nature of diagnostic tests performed and the outcome of surgical intervention, and provided their consent as first person or via a legal custodian including incognito procession of their data for research purposes as per the hospital's data protection policy. All participants provided the required written informed consent. The study acted in accordance with the tenets of the Declaration of Helsinki (2013 revision). All surgical procedures described herein were undertaken by an experienced retina surgeon (HG).

\section{Surgical Technique}

The surgical technique used in the present study was described in detail in a previous publication. ${ }^{12}$ Briefly the technique consisted of standard 3-port 23-gauge PPV and posterior hyaloid dissection (PHD), followed by modified 
ILM flap technique (IFT). We routinely used intravitreal triamcinolone acetonide (IVTA) for identification of the posterior hyaloid followed by induction of posterior vitreous detachment (PVD) by applying active aspiration using the vitreous cutter over the $\mathrm{ONH}$. An aspiration pressure of approximately $300 \mathrm{mmHg}$ usually was sufficient to induce PVD. Dissection of the posterior hyaloid was then continued as far as the equator. By default, we used IVTA for identification of the ILM. In cases of difficult visualization, we resorted to ILM-blue stain (D.O.R.C. Dutch Ophthalmic Research Center (International) B.V., The Netherlands) under air for 2 mins. We used the direct pinching technique using 23gauge Eckardt's end-gripping forceps (D.O.R.C. Dutch Ophthalmic Research Center (International) B.V., The Netherlands), and then continued the ILM maculorrhexis for an area of at least 2 disc diameters (DD) around the hole. ILM was not completely lifted off the retinal surface, rather peeling was stopped at the edges of the hole creating a free-floating flap that was left attached all around the edges of the hole. No further manipulation of the flap was attempted. That was followed by fluid-air exchange and finally air/hexafluoroethane (C2F6) exchange in a nonexpansile concentration (14\%). (Supplemental digital con tent, video 1 demonstrates the modified IFT using ILM-Blue stain). After surgery, we asked the patient to maintain face-down position whenever possible for 1 week or until half of the gas bubble was absorbed.

\section{Post-Operative Follow-Up}

Follow-up scheme during the post-operative period included 1st post-operative day, 1 week, 1 month, then 3-monthly visits thereafter. We categorized patients into subgroups according to the pattern of hole closure and grade of recovery of EZ and outer retinal layers including the external limiting membrane (ELM) and the inner segment/outer segment (IS/OS) photoreceptors junction layers. BCVA was assessed in each visit and post-operative complications secondary to surgical intervention were recorded for later correlation between these parameters.

\section{Pattern Of Hole Closure}

Group 1, U-pattern closure (closed hole with normal foveal contour). Group 2, V-pattern closure (closed hole with steep foveal contour). Group 3, W-pattern closure (edges of macular hole were flattened against the RPE, though with persistent full-thickness defect in the neurosensory retina). ${ }^{11}$

\section{Grade Of EZ, ELM And IS/OS Layers Recovery}

Group 1, grade 1, fully recovered EZ with uninterrupted ELM and IS/OS layers. Group 2, grade 2, disrupted EZ with interrupted ELM or IS/OS layers or both. Group 3, grade 3, included patients who had W-pattern closure.

Table I Baseline Patients' Data

\begin{tabular}{|c|c|c|c|c|c|c|c|c|c|c|c|c|}
\hline $\mathbf{S N}$ & A & G & $\mathbf{L}$ & $\begin{array}{l}\text { Pre-BCVA } \\
\text { (Decimal) }\end{array}$ & $\begin{array}{l}\text { Pre-MLD } \\
(\mu)\end{array}$ & $\begin{array}{l}\text { MH } \\
\text { Stage }\end{array}$ & $\begin{array}{l}\text { DUS } \\
\text { (Mo.) }\end{array}$ & $\begin{array}{l}\text { FUP } \\
\text { (Mo.) }\end{array}$ & $\begin{array}{l}\text { Post-operative } \\
\text { Foveal } \\
\text { Microstructure }\end{array}$ & $\begin{array}{l}\text { Closure } \\
\text { Type }\end{array}$ & $\begin{array}{l}\text { Post-BCVA } \\
\text { (Decimal) }\end{array}$ & Complications \\
\hline I & 15 & $M$ & OS & 0.05 & 542 & IV & 1.5 & 6 & Unrestored & $u$ & 0.2 & Cataract \\
\hline 2 & 24 & $M$ & OD & 0.01 & 502 & IV & 6 & 12 & Unrestored & v & 0.2 & - \\
\hline 3 & 7 & $M$ & OS & 0.01 & 473 & IV & 1.5 & 10 & Unrestored & $U$ & 0.05 & Cataract \\
\hline 4 & 20 & $M$ & OS & 0.1 & 413 & IV & 1 & 5 & Unrestored & $u$ & 0.63 & - \\
\hline 5 & 16 & $M$ & OS & 0.05 & 808 & IV & 12 & 6 & Unrestored & $U$ & 0.25 & - \\
\hline 6 & 11 & $M$ & OD & 0.125 & 590 & IV & 8 & 9 & Unrestored & V & 0.125 & - \\
\hline 7 & 30 & $M$ & OD & 0.01 & 667 & IV & 12 & 10 & - & w & 0.125 & Cataract \\
\hline 8 & 16 & M & OS & 0.25 & 225 & ॥ & 2 & 9 & Fully Restored & $\cup$ & 0.25 & - \\
\hline 9 & 28 & $M$ & OS & 0.25 & 467 & IV & 1.5 & 7 & - & w & 0.2 & - \\
\hline 10 & 24 & $M$ & OS & 0.01 & 509 & IV & 4 & 8 & Unrestored & V & 0.2 & - \\
\hline 11 & 14 & $M$ & OD & 0.05 & 725 & IV & 1.5 & 5 & Unrestored & v & 0.4 & - \\
\hline 12 & 13 & $M$ & OS & 0.05 & 433 & IV & 12 & 7 & Unrestored & $U$ & 0.25 & - \\
\hline 13 & 11 & $M$ & OS & 0.03 & 725 & IV & 2.5 & 4.5 & - & w & 0.01 & Cataract \\
\hline 14 & 16 & $M$ & OS & 0.01 & 250 & $\|$ & 2 & 4 & Unrestored & $U$ & 0.05 & - \\
\hline 15 & 15 & $M$ & OS & 0.1 & 833 & IV & 1 & 7 & Unrestored & v & 0.25 & - \\
\hline 16 & 10 & $M$ & OD & 0.05 & 825 & IV & 12 & 4 & Unrestored & $u$ & 0.125 & - \\
\hline
\end{tabular}

Abbreviations: A, Age; DUS mo., Duration prior to surgery in months; FUP mo., Follow-up in months; G, Gender; L, Laterality; $\mu$, micron; OD, Oculus dexter; OS, Oculus sinister; Post-BCVA, Post-operative best-corrected visual acuity; Pre-BCVA, Pre-operative best-corrected visual acuity; Pre-MLD, Pre-operative minimum linear diameter; $\mathrm{SN}$, serial number. 


\section{Statistical Methodology}

Bartlett's test for homogeneity of variances revealed that the assumption of equal variances in the data submitted for analysis was true. Statistical analysis was performed for all determinations including calculation of the mean, standard deviation (SD), standard error (SE) and t-value at level $\mathrm{p}<0.05$. The Student's T-Test compared means for two groups of variables, whereas Pearson's correlation coefficient checked the correlation between the variables tested. The value " $r$ " was checked on " $r$ " table to find out statistical significance.

\section{Results}

\section{Demographic Data}

We examined 16 eyes of 16 consecutive patients with TMH. All patients were males. At the time of

Table 2 Baseline Patients' Characteristics

\begin{tabular}{|l|l|}
\hline Baseline Characteristic & $\mathbf{N}=16$ \\
\hline Age (years) & 17 \\
Mean & $1(6 \%)$ \\
$<10$ & $11(69 \%)$ \\
I0-20 & $4(25 \%)$ \\
\hline 20 & \\
\hline Gender & $16(100 \%)$ \\
Male & \\
\hline BCVA (logMAR) & 1.4 \\
Mean & $11(69 \%)$ \\
$>$ I & $3(18.7 \%)$ \\
I-0.7 & $2(12.5 \%)$ \\
$<0.7$ & \\
\hline MLD ( $\mu)$ & 562 \\
Mean & $2(12.5 \%)$ \\
$<400$ & $8(50 \%)$ \\
$400-600$ & $3(18.7 \%)$ \\
$60 I-800$ & $3(18.7 \%)$ \\
$>800$ & \\
\hline Disease duration (months) & 5 \\
Mean & $9(56 \%)$ \\
I-3 & $2(12.5 \%)$ \\
$>3-6$ & $5(31 \%)$ \\
\hline $6-12$ & 7 \\
\hline Follow-up (months) & $7(44 \%)$ \\
Mean & $9(56 \%)$ \\
$4-6$ & \\
$>6-12$ & \\
\hline
\end{tabular}

Abbreviations: BCVA, best-corrected visual acuity; logMAR, logarithm of the minimum angle of resolution; $\mu$, micron; MLD, minimum linear diameter; $N$, number. enrollment in the study, average patient age was 17 years (range 7-30; SE 1.6), average MLD was $562 \mu$ (range 225-833; SE 47.5), mean BCVA was 1.4 logMAR (range 2-0.6; SE 0.1). Mean time interval between trauma and surgery was 5 months (range 112; SE 1.1). At the conclusion of the study, all participants completed the required minimum follow-up period, mean follow-up duration was 7 months (range 412; SE 0.6). Baseline patients' data and characteristics are summarized in Tables 1 and 2.

\section{Surgical Outcome}

\section{Closure Pattern Of TMH And EZ Recovery}

In terms of pattern of hole closure, group 1 (U-pattern) included 8 eyes (50\%). Group 2 (V-pattern) included 5 eyes (31.2\%). Group 3 (W-pattern) included 3 eyes (18.7\%). Figures $1-4$. In terms of EZ recovery, group 1 (fully recovered EZ) included 1 eye (6\%). Group 2 (disrupted EZ) included 12 eyes (75\%).

\section{Visual Acuity}

Twelve patients (75\%) had improved BCVA, 2 patients (12.5\%) remained stable and 2 patients (12.5\%) experienced vision deterioration. Only one patient achieved final $\mathrm{BCVA} \leq 0.3 \log \mathrm{MAR}$. Mean BCVA was $0.8 \log \mathrm{MAR}$ (range 2-0.2; SE 0.1). Mean improvement was 5 lines (p 0.02).

\section{Complications}

Four eyes $(25 \%)$ developed cataract that eventually required phacoemulsification. Table 3 summarizes the surgical outcome.

\section{Correlation Between Baseline MLD And Duration Of TMH Versus Pattern Of Closure And Recovery Of EZ}

Neither baseline MLD nor duration of TMH were significant factors in determining pattern of hole closure or grade of EZ recovery.

\section{Correlation Between Baseline MLD, Duration Of TMH Versus Final BCVA}

Neither baseline MLD nor duration of TMH were significant parameters in determining final BCVA.

\section{Discussion}

In this series, we employed the modified IFT technique in the treatment of TMH. We detected U-, V- and 


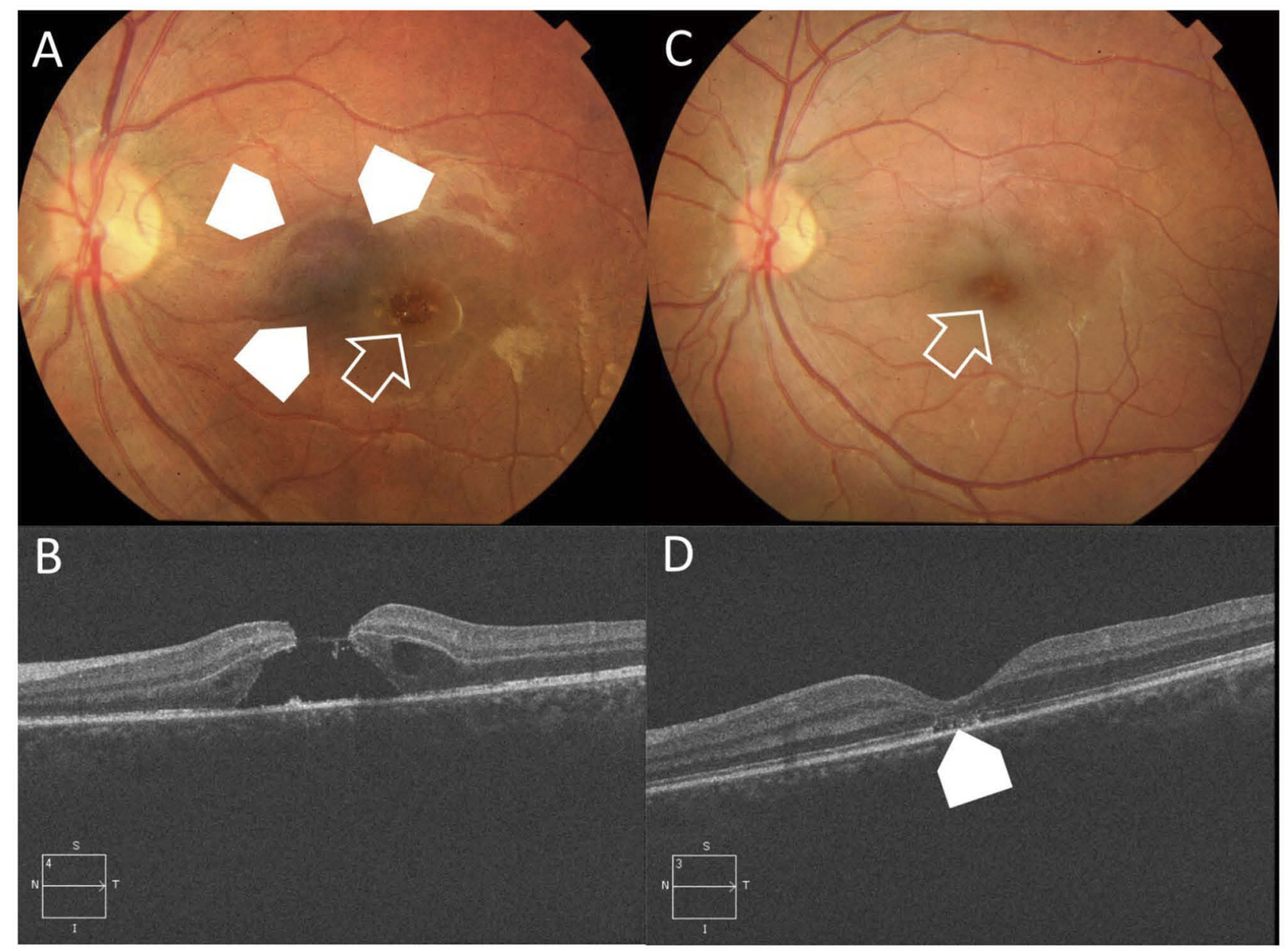

Figure I Case \# I. (A) Color photo of the left eye of a I5-year-old male patient. The patient sustained blunt trauma to the left eye by a belt buckle approximately 45 days earlier. His BCVA was 0.05 decimal. The posterior pole showed a FTMH < I/3 DD (white arrow). The hole was surrounded by sub-macular hemorrhage (white arrow-heads). (B) High-definition 5-line raster OCT image of the same eye showed FTMH with MLD 542 $\mu$. Note the cystic thickening at the edges of the hole. (C) Color photo of the same eye 6 months after PPV and modified IFT, showed successful hole closure (white arrow). Note resolution of previously noted sub-macular hemorrhage. His final BCVA was 0.2 decimal. (D) High-definition 5-line raster OCT image post-operatively showed U-type closure. The ELM and IS/OS were not restored (white arrow-head).

W-patterns of closure in $50 \%, 31.2 \%$ and $18.7 \%$ of eyes, respectively. In terms of improved BCVA, though the majority of our patients (93.7\%) did not achieve BCVA $\leq 0.4 \operatorname{logMAR}$ (decimal equivalent $\geq 0.4$ ), the overall mean visual gain was 5 lines compared to baseline. The fore-mentioned limited BCVA score could be attributed to failure of recovery of EZ and W-type closures that collectively occurred in 15 out of 16 patients (93.7\%), or to concomitant involvement of the macula by diffuse RPE changes secondary to trauma. In comparison, García-Arumí et al, ${ }^{13}$ achieved macular hole closure in $92.8 \%$ of 14 eyes with TMH. BCVA improved by $\geq 4$ lines. In addition to PPV and PHD, the authors used platelet concentrate as adjuvant to promote hole closure. No OCT assessment was included in their study. Kuhn et al, ${ }^{14}$ achieved hole closure in all 17 eyes with TMH included in their series following PPV and ILM peel. BCVA improved $\geq 2$ lines in $94 \%$ of eyes. In comparison with the present series in which the mean baseline MLD was $562 \mu$, Kuhn et al ${ }^{14}$, operated exclusively on stage 2 or $3 \mathrm{TMH}$. Moreover, Kuhn et $\mathrm{al}^{14}$, defined macular hole closure as disappearance of sub-retinal fluid and flattening of the hole edges. In the absence of OCT assessment of macular hole closure type, the authors might have included W-type closure in their successful cases. In addition, the absence of assessment of foveal microstructure restoration is an important factor to consider given that their mean final BCVA did not exceed 20/80, and whether that visual outcome could be attributed solely to trauma-related 


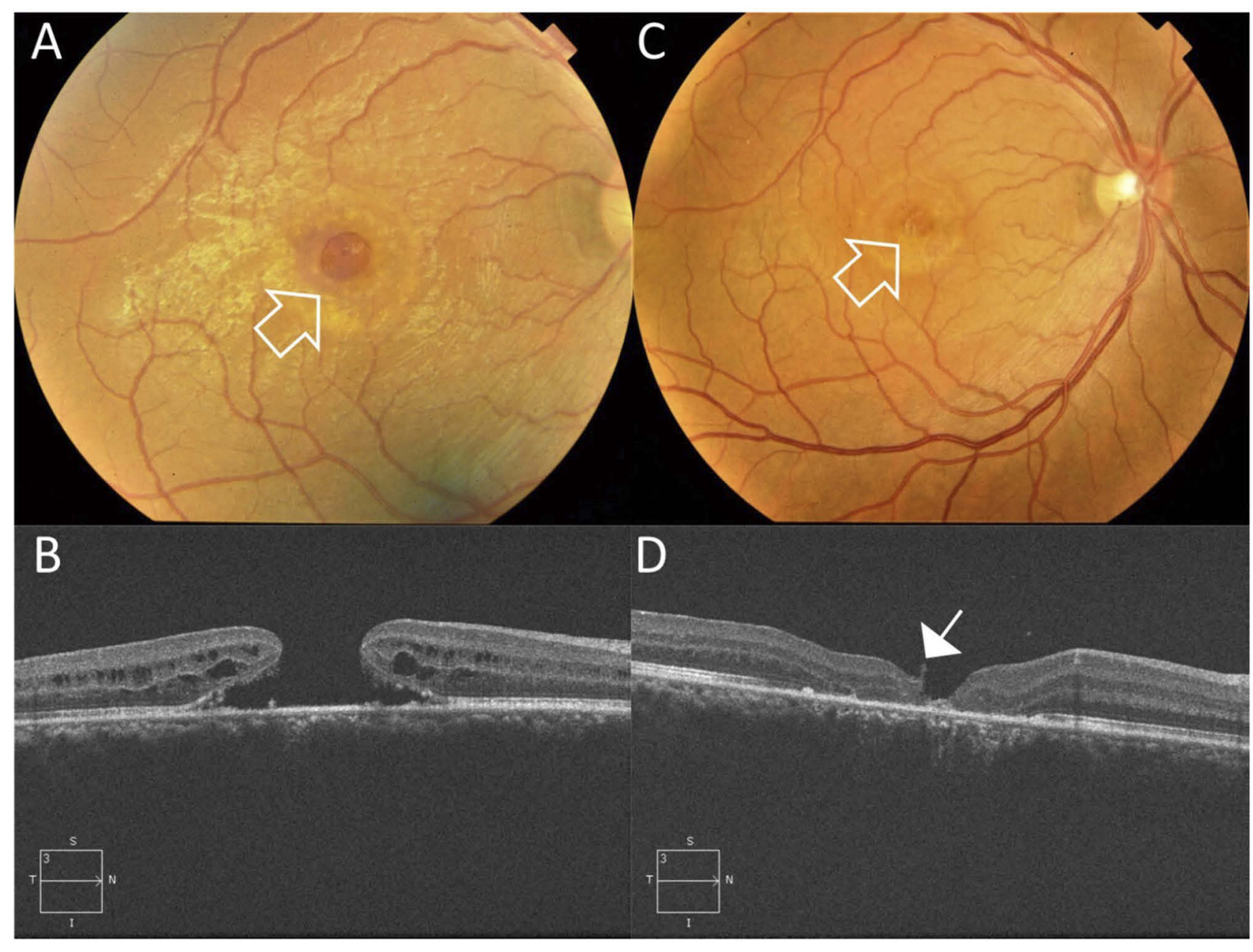

Figure 2 Case \# 7. (A) Color photo of the right eye of a 30-year-old male patient. The patient sustained blunt trauma to the right eye by a donkey's kick since 12 months. His BCVA was 0.01 decimal. The posterior pole showed a large FTMH I/3 - I/2 DD (white arrow). (B) High-definition 5-line raster OCT image of the same eye showed FTMH with MLD 667 $\mu$. Note the cystic thickening at the edges of the hole. (C) Color photo of the same eye 10 months after PPV and modified IFT, showed successful hole closure (white arrow). His final BCVA was 0.125 decimal. (D) High-definition 5-line raster OCT image post-operatively showed W-type closure. Note the edge of the ILM flap (white arrow).

foveal damage and not to failed foveal microstructure restoration. Johnson et $\mathrm{al}^{2}$, studied retrospectively 25 eyes with TMH. The authors achieved an overall closure rate of $96 \%$. Mean visual gain in $84 \%$ of their cases was $\geq 2$ lines. The majority of eyes (84\%) included in that series had stage 2 or 3 holes. The authors did not have standard surgical approach in all cases, with only 3 eyes having ILM peel and almost half of the cases had application of autologous serum as an adjuvant to enhance closure of the hole. The study did not include OCT evaluation. Accordingly, there were no means to assess the type of hole closure in their successful cases and the reason why their mean final BCVA did not exceed 20/80. Ou et $\mathrm{al}^{5}$, reported closure rate of $75 \%$ in 4 infants operated for TMH. The cause of trauma was shaken baby syndrome (SBS) in all cases with associated vitreous and retinal hemorrhages. The mean macular hole diameter was $700 \mu$. Weichel and Colyer ${ }^{3}$, performed PPV, PHD without ILM peel on 12 eyes with TMH secondary to combat ocular trauma. The authors achieved closure rate of $67 \%$. OCT assessment was not included in their study, accordingly, they did not provide information neither on baseline hole diameter nor on post-operative foveal microstructure status. Ghoraba et $\mathrm{al}^{15}$, studied retrospectively 22 eyes with TMH. The authors performed PPV and ILM peel for all cases while using 2 different tamponades (perfluoropropane gas; C3F8 vs silicone oil) to compare the anatomic and visual outcome between both types in 2 subgroups (13 and 9 eyes, respectively). The authors had initial overall closure rate of $81.8 \%$ and $90.9 \%$ after second operation. Visual gain was significantly better in the 


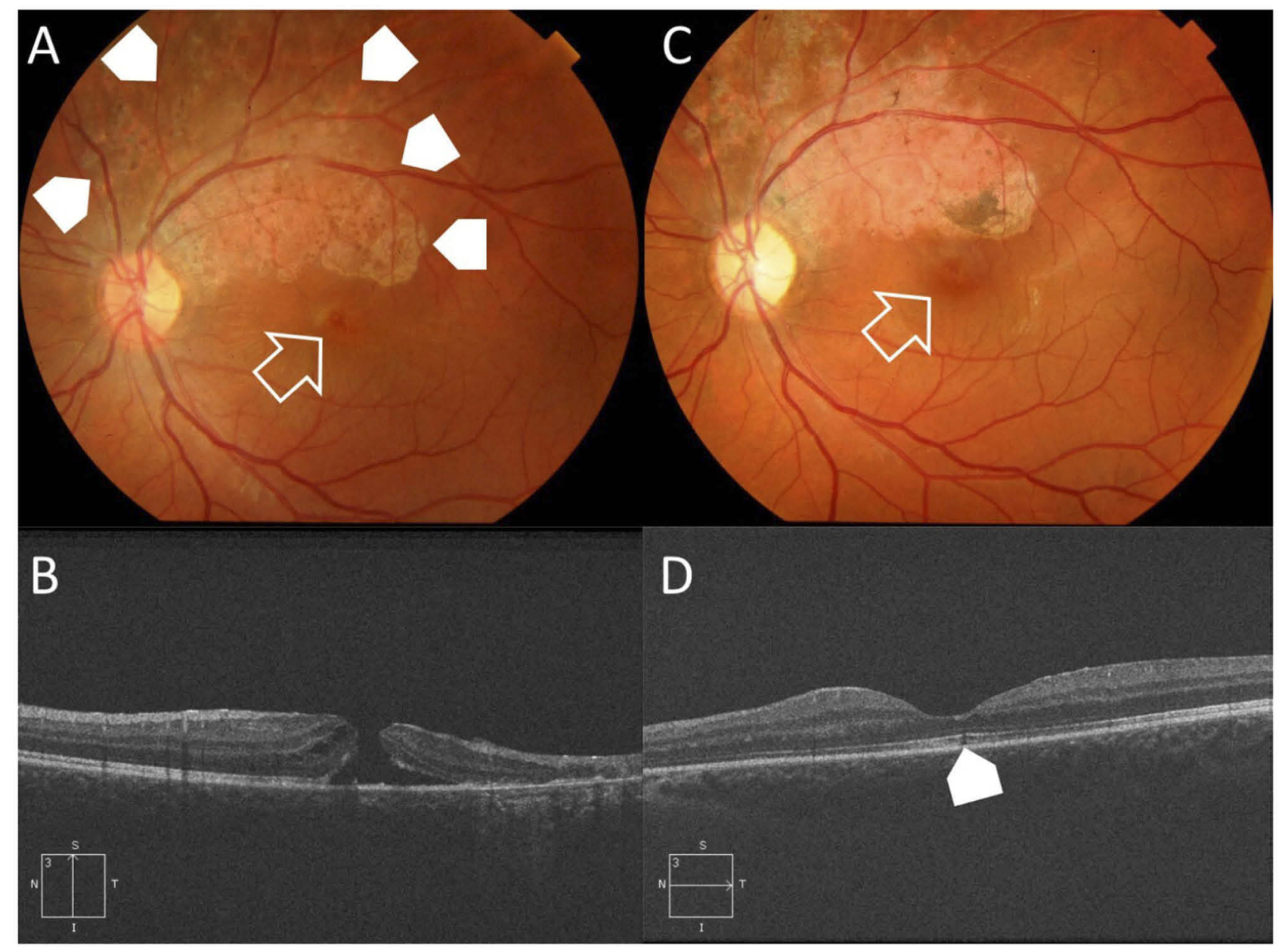

Figure 3 Case \# 8. (A) Color photo of the left eye of a 16-year-old male patient. The patient sustained blunt trauma to the left eye by a stick approximately 2 months earlier. His BCVA was 0.25 decimal. The posterior pole showed a small FTMH (white arrow). Note, the area of diffuse RPE mottling in the superior vicinity of the hole denoting the chronic course (white arrow-heads). (B) High-definition 5-line raster OCT image of the same eye showed FTMH with MLD 225 $\mu$. Note the cystic thickening at the edges of the hole. (C) Color photo of the same eye 9 months after PPV and modified IFT, showed successful hole closure (white arrow). His final BCVA was unchanged. (D) High-definition 5-line raster OCT image post-operatively showed U-type closure. The ELM and IS/OS showed sub-foveal dehiscence (white arrow-head).

C3F8 group compared to the silicone oil group (4 lines and 3 lines, respectively). Similarly, closure rates were significantly higher in the C3F8 group. Though OCT examination was included in their study, there was no mention on the baseline hole diameter or the correlation between the reported visual outcome and the foveal microstructure Table 4 . In the present study, we adopted Casini modification ${ }^{9}$ of the classic inverted ILM flap technique described by Michalewska. ${ }^{16}$ To our knowledge, this is the first report on the outcome of modified IFT in TMH. Our results demonstrated that modified IFT was effective in promoting macular hole closure and in promoting significant improvement of mean final BCVA. Failure of restoration of EZ remained a major pathological feature that was not rectified by modified IFT. Whether, the trauma sustained by the macula is a significant contributing factor to failed restoration of EZ is yet to be elucidated by histopathological studies. In our hands, we found that modified IFT was easier to execute and less traumatic as it avoided any manipulation that might inflict further trauma to the macular area during ILM massage at the margins of the hole or to the RPE at the base of the hole while attempting to fold the ILM flap inside it as described by Michalewska. ${ }^{16}$ We did not attempt to perform directional fluid-air exchange as described by Casini to allow the air to press on one side of the residual ILM flap to cover the hole. ${ }^{9}$ We consider this maneuver unnecessary as the ILM flap in our cases crumbled on itself and inside the hole on its own during 


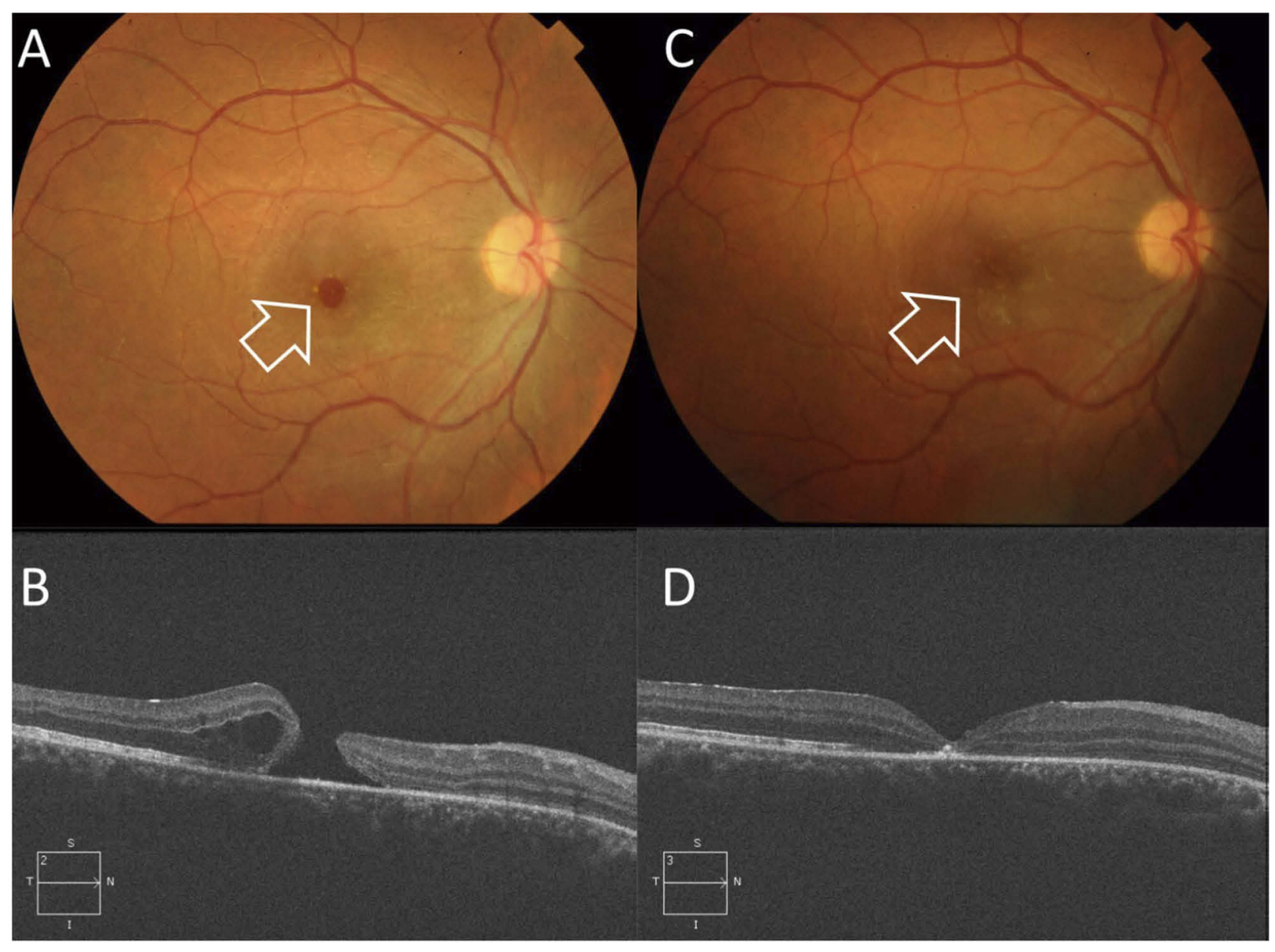

Figure 4 Case \# 10. (A) Color photo of the left eye of a 24-year-old male patient. The patient sustained blunt trauma to the left eye by an air hose since 4 months. His BCVA was 0.01 decimal. The posterior pole showed a FTMH $<$ I/3 DD (white arrow). (B) High-definition 5-line raster OCT image of the same eye showed FTMH with MLD $509 \mu$. Note the cystic thickening at the edges of the hole. (C) Color photo of the same eye 8 months after PPV and modified IFT, showed successful hole closure (white arrow). His final BCVA was 0.2 decimal. (D) High-definition 5 -line raster OCT image post-operatively showed V-type closure.

the post-operative period in most of the cases. Similar finding was reported by Yamashiro et al, ${ }^{17}$ who found that remnants of the ILM might get adsorbed into the depth of the hole after surgery while the RPE pumps out fluid from the cuff of neurosensory detachment around the hole edges. The present study corroborates the hypotheses from other studies that shearing of the foot plates of the Müller cells during ILM peel and incomplete lifting of the ILM flap that remained anchored to the hole edges would provide an adequate stimulus to initiate the healing process. ${ }^{8,9,17-19}$ Attempts to manipulate the flap as folding it over the hole or tucking inside the hole are unnecessary and might induce further trauma to the RPE. ${ }^{9,19}$ In a previously published comparative study, we reported our findings on the outcomes of comparing the modified IFT and conventional ILM peel in TMH. We found that modified IFT yielded
Table 3 Post-Operative Anatomical And Functional Outcome

\begin{tabular}{|l|l|}
\hline Post-Operative Outcome & $\mathbf{N}=16$ \\
\hline $\begin{array}{l}\text { Closure type } \\
\text { U-type } \\
\text { V-type }\end{array}$ & $8(50 \%)$ \\
W-type & $5(31.2 \%)$ \\
\hline Foveal microstructure & $3(18.7 \%)$ \\
Fully restored & \\
Not restored & $1(6 \%)$ \\
Flat hole (Persistent NS defect) & $12(75 \%)$ \\
\hline BCVA (logMAR) & $3(18.7 \%)$ \\
Mean & \\
$>$ I & 0.8 \\
I-0.4 & $3(18.7 \%)$ \\
$<0.4$ & $12(75 \%)$ \\
\hline Cataract formation & $\mathrm{I}(6 \%)$ \\
\hline
\end{tabular}

Abbreviations: BCVA, best-corrected visual acuity; logMAR, logarithm of the minimum angle of resolution; $\mathrm{N}$, number. 
Table 4 Review Of Studies On PPV With And Without ILM Peel For Traumatic Macular Hole

\begin{tabular}{|c|c|c|c|c|}
\hline Author & $\begin{array}{l}\text { No. } \\
\text { Of } \\
\text { Eyes }\end{array}$ & Surgical Technique & Anatomical Closure (\%) & $\begin{array}{l}\text { Functional Outcome (Mean Final } \\
\text { BCVA) }\end{array}$ \\
\hline $\begin{array}{l}\text { García-Arumí et } \\
\text { al, } 1997 \text { [13] }\end{array}$ & 14 & $\begin{array}{l}\text { PPV - platelet concentrate } \\
\text { SF6 }\end{array}$ & 92.8 & $\geq 4$ lines \\
\hline $\begin{array}{l}\text { Kuhn et al, } 2001 \\
{[14]}\end{array}$ & 17 & $\begin{array}{l}\text { PPV - ILM peel } \\
\text { SF6 }\end{array}$ & 100 & 6 lines \\
\hline $\begin{array}{l}\text { Johnson et al, } \\
200 \text { I [2] }\end{array}$ & 25 & $\begin{array}{l}\text { PPV - ILM peel (3 cases) } \\
\text { C3F8 } \\
\text { Autologous serum (1 } 2 \text { cases) }\end{array}$ & 96 & $\geq 2$ lines in $84 \%$ of cases \\
\hline Ou et al, 2006 [5] & 4 & $\begin{array}{l}\text { PPV } \\
\text { ILM peel ( } 4 \text { cases) } \\
\text { SO, Air, C3F8, } \\
\text { no tamponade (I case) }\end{array}$ & 75 & Poor visual outcome \\
\hline $\begin{array}{l}\text { Weichel and } \\
\text { Colyer, } 2009 \text { [3] }\end{array}$ & 12 & $\begin{array}{l}\text { PPV } \\
\text { SO, C3F8, SF6 }\end{array}$ & 67 & $\begin{array}{l}\text { Insignificant improvement between cases } \\
\text { with and without hole closure }\end{array}$ \\
\hline $\begin{array}{l}\text { Ghoraba et al, } \\
2012[15]\end{array}$ & 22 & $\begin{array}{l}\text { PPV - ILM peel - SO } \\
(9 \text { cases }) \\
\text { PPV - ILM peel } \\
\text { C3F8 (I3 cases })\end{array}$ & $\begin{array}{l}81.8 \% \text { primary closure } \\
90.9 \% \text { after re-operation }\end{array}$ & 3 lines (SO group), 4 lines (C3F8 group) \\
\hline $\begin{array}{l}\text { Ghoraba et al, } \\
2019[12]\end{array}$ & 40 & $\begin{array}{l}\text { PPV - ILM peel - C2F6 } \\
\text { ( } 28 \text { cases) } \\
\text { PPV - modified IFT - C2F6 } \\
\text { (I } 2 \text { cases) }\end{array}$ & $\begin{array}{l}75 \% \\
92 \%\end{array}$ & $\begin{array}{l}2.5 \text { lines } \\
5 \text { lines }\end{array}$ \\
\hline $\begin{array}{l}\text { Current study, } \\
2019\end{array}$ & 16 & PPV - modified IFT - C2F6 & $\begin{array}{l}\text { U-pattern (50\%), V-pattern } \\
(3 \mathrm{I} .2 \%)), \mathrm{W} \text {-pattern (I8.7\%) }\end{array}$ & 5 lines \\
\hline
\end{tabular}

Abbreviations: BCVA, best-corrected visual acuity; C2F6, hexafluoroethane; C3F8, perfluoropropane; IFT, ILM flap technique; ILM, internal limiting membrane; No., number; PPV, pars plana vitrectomy; SF6, sulfurhexafluoride; SO, silicone oil.

superior hole closure rate ( $92 \%$ vs $75 \%)$, and better final BCVA (5 lines gain vs 2.5 lines gain) than conventional ILM peel approach. ${ }^{12}$ We acknowledge the limitations of the present study that included its retrospective design, which caused inhomogeneity of the baseline characteristics of recruited patients in terms of baseline MLD, time lapse prior to surgery, and duration of follow-up. The relatively small sample size, and lack of concurrent comparison group using other techniques for treating TMH were other important limitations.

\section{Conclusion}

Modified IFT is effective in promoting macular hole closure and improving visual acuity in patients with $\mathrm{TMH}$, but not in promoting recovery of the EZ and outer retinal layers. This is a relatively undemanding surgical maneuver particularly when compared to other more complex approaches, though its efficacy needs to be consolidated through further studies comparing modified IFT to other surgical techniques for TMH.

\section{Data Availability}

The statistical data used to support the findings of this study were included within the article. The data collected from history taking and clinical examination of patients recruited in the current study are confidential. Access to these data is restricted by Magrabi Eye Hospital, Tanta, Egypt, in accordance with the hospital's patients' data protection policy. Data are available for researchers who meet the criteria for access to confidential data through contacting the hospital's medical director Professor Hammouda Ghoraba (hghoraba@email.com). 


\section{Disclosure}

The authors declare no conflicts of interest regarding the publication of this article. The authors did not receive funding from any institution in support of this publication.

\section{References}

1. Aaberg TM, Blair CJ, Gass JDM. Macular holes. Am J Ophthalmol. 1970;69:555-562. doi:10.1016/0002-9394(70)91620-х

2. Johnson RN, McDonald HR, Lewis H, et al. Traumatic macular hole. Ophthalmology. 2001;108:853-857. doi:10.1016/s0161-6420 (00)00650-3

3. Weichel ED, Colyer MH. Traumatic macular holes secondary to combat ocular trauma. Retina. 2009;29:349-354. doi:10.1097/ IAE.0b013e31818d4b82

4. Kunjukunju N, Navarro A, Oliver S, et al. Bilateral macular hole formation secondary to sclopetaria caused by shockwaves transmitted by a posterior vector: case report. BMC Ophthalmology. 2010;10:6. doi:10.1186/1471-2415-10-6

5. Ou JI, Moshfegi DM, Tawansy K, Sears JE. Macular hole in the shaken baby syndrome. Arch Ophthalmol. 2006;124:913-915. doi:10.1001/archopht.124.6.913

6. Rossi T, Boccassini B, Esposito L, et al. The pathogenesis of retinal damage in blunt eye trauma: finite element modeling. Invest Ophthalmol Vis Sci. 2011;52(7):3994-4002. doi:10.1167/iovs.10-6477

7. Shukla D. Secondary macular holes: when to jump in and when to stay out. Expert Rev Ophthalmol. 2013;8(5):437-446. doi:10.1586/ 17469899.2013.844069

8. Smiddy WE, Feuer W, Cordahi G. Internal limiting membrane peeling in macular hole surgery. Ophthalmology. 2001;108:1471-1478. doi:10.1016/s0161-6420(00)00645-x

9. Casini G, Mura M, Figus M, et al. Inverted internal limiting membrane flap technique for macular hole surgery without extra manipulation of the flap. Retina. 2017;37:2138-2144. doi:10.1097/ IAE.0000000000001470

10. Ip MS, Baker BJ, Duker JS, et al. Anatomical outcomes of surgery for idiopathic macular hole as determined by optical coherence tomography. Arch Ophthalmol. 2002;120:29-35. doi:10.1001/archopht. 120.1.29

Clinical Ophthalmology

\section{Publish your work in this journal}

Clinical Ophthalmology is an international, peer-reviewed journal covering all subspecialties within ophthalmology. Key topics include: Optometry; Visual science; Pharmacology and drug therapy in eye diseases; Basic Sciences; Primary and Secondary eye care; Patient Safety and Quality of Care Improvements. This journal is indexed on PubMed

Submit your manuscript here: https://www.dovepress.com/clinical-ophthalmology-journal
11. Imai M, Iijima H, Gotoh T, Tsukahara S. Optical coherence tomography of successfully repaired idiopathic macular holes. $\mathrm{Am} \mathrm{J}$ Ophthalmol. 1999;128:621-627. doi:10.1016/s0002-9394(99)002 00-7

12. Ghoraba HH, Leila M, Ghoraba H, Heikal MA, Elgemai EEM. Comparative study between pars plana vitrectomy with internal limiting membrane peel and pars plana vitrectomy with internal limiting membrane flap technique for management of traumatic full thickness macular holes. J Ophthalmol. 2019;2019:10. Article ID 1959082. doi: $10.1155 / 2019 / 1959082$

13. García-Arumí J, Corcostegui B, Cavero L, Sararols L. The role of vitreoretinal surgery in the treatment of posttraumatic macular hole. Retina. 1997;17:372-377. doi:10.1097/00006982-19970900000003

14. Kuhn F, Morris R, Mester V, Witherspoon C. Internal limiting membrane removal for traumatic macular holes. Ophthalmic Surg Lasers. 2001;32:308-315.

15. Ghoraba HH, Ellakwa AF, Ghali AA. Long term result of silicone oil versus gas tamponade in the treatment of traumatic macular holes. Clin Ophthalmol. 2012;6:49-53. doi:10.2147/OPTH.S22061

16. Michalewska Z, Michalewski J, Adelman RA, Nawrocki J. Inverted internal limiting membrane flap technique for large macular holes. Retina. 2010;117:2018-2025.

17. Yamashiro K, Kinoshita-Nakano E, Ota T, Jingami Y, Nakata I, Hayashi H. Floating flap of internal limiting membrane in myopic macular hole surgery. Graefes Arch Clin Exp Ophthalmol. 2018;256:693-698. doi:10.1007/s00417-018-3936-6

18. Michalewska Z, Michalewski J, Dulczewska-Cichecka K, Adelman RA, Nawrocki J. Temporal inverted internal limiting membrane flap technique versus classic inverted internal limiting membrane flap technique. Retina. 2015;35:1844-1850. doi:10.1097/IAE.000000000 0000555

19. Chung CY, Wong DSH, Li KKW. Is it necessary to cover the macular hole with the inverted internal limiting membrane flap in macular hole surgery? A case report. BMC Ophthalmol. 2015;15:115. doi:10.1186/s12886-015-0104-1
Central and CAS, and is the official journal of The Society of Clinical Ophthalmology (SCO). The manuscript management system is completely online and includes a very quick and fair peer-review system, which is all easy to use. Visit http://www.dovepress.com/ testimonials.php to read real quotes from published authors. 